\title{
Split-Session Focus Group Interviews in the Naturalistic Setting of Family Medicine Offices
}

\author{
Michael D. Fetters, MD, MPH, $M A^{1}$ \\ Timotby C. Guetterman, $P b D^{1}$ \\ Debra Power, BA, BA ${ }^{2}$ \\ Donald E. Nease, Jr, $M D^{3}$ \\ 'Department of Family Medicine, Univer- \\ sity of Michigan, Ann Arbor, Michigan \\ ${ }^{2}$ Power Marketing Research, Ann Arbor, \\ Michigan \\ ${ }^{3}$ Department of Family Medicine, Univer- \\ sity of Colorado, Denver, Colorado
}

\begin{abstract}
PURPOSE When recruiting health care professionals to focus group interviews, investigators encounter challenges such as busy clinic schedules, recruitment, and a desire to get candid responses from diverse participants. We sought to overcome these challenges using an innovative, office-based, split-session focus group procedure in a project that elicited feedback from family medicine practices regarding a new preventive services model. This procedure entails allocating a portion of time to the entire group and the remaining time to individual subgroups. We discuss the methodologic procedure and the implications of using this approach for data collection.
\end{abstract}

METHODS We conducted split-session focus groups with physicians and staff in 4 primary care practices. The procedure entailed 3 sessions, each lasting 30 minutes: the moderator interviewed physicians and staff together, physicians alone, and staff alone. As part of the focus group interview, we elicited and analyzed participant comments about the split-session format and collected observational field notes.

RESULTS The split-session focus group interviews leveraged the naturalistic setting of the office for context-relevant discussion. We tested alternate formats that began in the morning and at lunchtime, to parallel each practice's workflow. The splitsession approach facilitated discussion of topics primarily relevant to staff among staff, topics primarily relevant to physicians among physicians, and topics common to all among all. Qualitative feedback on this approach was uniformly positive.

CONCLUSION A split-session focus group interview provides an efficient, effective way to elicit candid qualitative information from all members of a primary care practice in the naturalistic setting where they work.

Ann Fam Med 2016;14:70-75. doi: 10.1370/afm.1881.

\section{INTRODUCTION}

$\mathrm{T}$ he Office of Behavioral and Social Science Research of the National Institutes of Health recognizes the need for and acceptance of qualitative data collection in health sciences research, ${ }^{1}$ and the focus group interview is one commonly known and accepted method. ${ }^{1-5}$ Health sciences researchers often need to engage physicians and staff to understand office-based work, but implementing focus groups with all members of a practice has challenges related to contact and recruitment, sufficient incentives, and spillover of clinical work into scheduled meeting times. ${ }^{2}$ Additional issues include where to conduct the focus groups and how to conduct them when physicians and staff must be present to discuss workflow issues. A particular challenge arises when physician and staff participation are needed to understand topics of mutual relevance, such as workflow, but physician presence could deter staff from voicing their true opinions.

Originally developed for use in marketing research, the focus group interview is a well-described tool for collecting qualitative data in health care research. The modern focus group interview traces to the classic work of Merton et $\mathrm{al}^{6}$ in the mid-1950s that followed 2 decades of experimentation with nondirective interviewing. ${ }^{4}$ Focus group interviews eluci-

Michael D. Fetters, MD, MPH, MA

Department of Family Medicine

University of Michigan

1018 Fuller St

Ann Arbor, MI 48104-1213

mfetters@umich.edu 
date data that would not be accessible without group interaction ${ }^{5,7}$ in a short span of time $e^{4,5}$ and promote self-disclosure in a group environment about topics that may not emerge through other questioning. ${ }^{4,7}$ Researchers can learn the natural phrasings used by participants, and see how and for what kinds of data individuals will challenge each other. ${ }^{5}$

Focus group interviews have limitations, such as the inability to observe the interaction in the natural field setting, ${ }^{5}$ less researcher control over data generation (but more than with participant observation), ${ }^{5}$ and risks of groupthink or so-called herd mentality in the group. ${ }^{8}$ Researchers have criticized published articles that use focus groups for failing to report on participant interactions $^{9}$ and generating only superficial discussion of the topic. ${ }^{10}$ Some sensitive topics, especially in health care research, may be difficult to investigate in focus group interviews because individuals may feel uncomfortable disclosing information in front of others, although for certain subpopulations (eg, women of color), the setting may provide an environment with a sense of security to disclose information more candidly. ${ }^{7}$

While conducting research to explore an innovative, web-based system to enhance delivery of preventive services in primary care, we selected focus group interviews as our primary data collection approach as we sought participant interaction relative to workflow and delivery of preventive services. The study called for collection of opinions from both physicians and staff, which raised 3 concerns. The first concern was where to hold the focus groups as a neutral out-ofoffice site was both cost-prohibitive and difficult logistically. A second concern was how to time the focus groups to maximize participation, but avoid disrupting the office work. A third concern was whether power dynamics would inhibit staff from speaking candidly with physicians present.

We devised a novel solution, namely, office-based split-session focus groups. The procedure involved holding the focus groups in the office, but splitting time between the staff and clinicians to ensure interaction of all parties, while also having separate time for physicianonly and staff-only discussion. Our objectives are to describe how the focus groups were conducted using the split-session procedure in the naturalistic setting of the office, to present participant perspectives about the process and researcher observations, and to elaborate on implications of this approach for other researchers.

\section{METHODS}

\section{Design and Setting}

Our project, entitled Improving Prevention Delivery Using an Interactive Technology System (PreventIT), was funded by the Centers for Disease Control and Prevention under the R43 Small Business Innovation Research mechanism. The University of Michigan Institutional Review Board approved this research (ID\# HUM00012455). The primary aim of the project was to develop a prototype of an interactive information technology-based system for improving the delivery of preventive services. After the investigators developed paper prototypes of the new system, the research design called for initial formative testing with physicians and their staff, and with patients who would be potential users of the system. As the research team had specific questions about design, format, and content, focus group interviews were an ideal method for data collection. Although individuals participating in focus groups often have similar backgrounds based on sex, racial/ethnic features, or other commonalities, in this research, the unifying attribute among participants was the expertise of the staff and physicians working together in a primary care office.

Because of feasibility issues - both the time and effort required for staff to travel, and the prohibitive rental costs of an off-site location-we chose to use the practice offices for the collection of study data. The additional advantage was that the office was the naturalistic setting where the workflow occurred. Still, this choice of setting raised the problem of how to address issues related to a busy workflow. The solution was a novel split-session focus group interview approach, the framework of which is shown in Table 1. This approach involved the physicians and staff meeting together with the moderator, then the physicians meeting alone with the moderator, and then the staff meeting alone with the moderator.

\section{Participants and Recruitment}

As implementing health information technology affects virtually everyone in a practice, the project called for participation by physicians, office managers, staff, and patients. Community-based family physician offices served as the setting. Participants were recruited through an independent practice association in southeastern Michigan. The association maintained data about practice demographics so that we were able to perform intentional sampling based on specific characteristics. In our sampling, we sought 2 practices that were using an electronic health record and 2 practices that were not. In addition, we sought urban and suburban representation. The independent practice association contacted the offices to determine their interest in participating in the study. Each office received $\$ 1,000$ in compensation with the agreement that they would close their office to patient care for an hour. 
Table 1. Framework of the Split-Session Focus Group Approach

\begin{tabular}{|c|c|}
\hline Step & Comment \\
\hline \multirow{2}{*}{$\begin{array}{l}\text { 1. Conduct a joint session } \\
\text { with both physicians } \\
\text { and staff members }\end{array}$} & $\begin{array}{l}\text { Some aspects of project implementation required a joint dis- } \\
\text { cussion with all staff and physicians present }\end{array}$ \\
\hline & $\begin{array}{l}\text { Questioning is focused on aspects of the system that would } \\
\text { affect both parties }\end{array}$ \\
\hline \multirow{2}{*}{$\begin{array}{l}\text { 2. Dismiss staff so they } \\
\text { can prepare for patients }\end{array}$} & Staff members are able to follow regular practice workflow \\
\hline & $\begin{array}{l}\text { Physicians can be interviewed without staff present and make } \\
\text { comments about potentially sensitive staff issues without } \\
\text { concerns about offending anyone }\end{array}$ \\
\hline \multirow[t]{2}{*}{$\begin{array}{l}\text { 3. Interview physicians } \\
\text { only }\end{array}$} & $\begin{array}{l}\text { While staff are preparing patients, physicians often have rela- } \\
\text { tive down time }\end{array}$ \\
\hline & $\begin{array}{l}\text { Aspects affecting only the physicians could be asked and dis- } \\
\text { cussed efficiently without staff being onlookers }\end{array}$ \\
\hline $\begin{array}{l}\text { 4. Dismiss physicians to } \\
\text { resume clinical care }\end{array}$ & $\begin{array}{l}\text { Physicians can complete patient care as usual and even } \\
\text { extend into the noon hour without disruption to the usual } \\
\text { work schedule }\end{array}$ \\
\hline \multirow{2}{*}{$\begin{array}{l}\text { 5. Interview staff only } \\
\text { when patient care is } \\
\text { completed (eg, before, } \\
\text { during, or after lunch) }\end{array}$} & $\begin{array}{l}\text { In the usual workflow, staff complete preparing patients for } \\
\text { physicians and are available for noon-time discussions }\end{array}$ \\
\hline & $\begin{array}{l}\text { With physicians out of the room, staff may be more com- } \\
\text { fortable stating opinions about implementation that } \\
\text { they might otherwise feel too inhibited to voice if their } \\
\text { employer were present }\end{array}$ \\
\hline
\end{tabular}

system like this to increase your revenue? Why or why not?") or only to staff (eg, "From a workflow perspective, does PreventIT seem like an improvement, or a hindrance?"). We recognized that staff might feel inhibited about discussing some topics candidly in front of the physicians (their employers), which reinforced our plan to interview subgroups separately.

\section{Evaluation of the Split-Session Approach}

Realizing that the split-session approach was novel, and with an eye toward developing this article on research methods, we included in the interview guide questions about the use of the split-session format. We asked, "We'd like to gather your

\section{Data Collection Procedures}

Because the PreventIT system was designed to decrease the labor associated with delivering preventive services during a general physical visit, we used a role play of the physician and patient interacting as would happen during such a visit to show, rather than tell, the participants how PreventIT would affect their workflow. ${ }^{11,12}$ We coupled informational handouts and sample designs as stimulus material about the prototype.

\section{Data Collection Instrument}

The research team worked together to create the focus group interview guide based on specific questions about anticipated use of PreventIT, integration into workflow, usability, and interface design issues. During development of the questions for the focus group interviews, it became clear that some topics affected both physicians and staff, while others were relevant only to physicians (eg, "Is it important for a feedback on the process we used for conducting the initial sessions with you and your staff. Specifically, we're looking for comments about the process of holding an initial session with you and your staff and then splitting into 2 additional sessions with staff and physicians separated. How did you feel about the way we scheduled the focus group sessions?" In addition, we recorded field notes about our observations. We used a qualitative approach and organized the data thematically in a matrix. ${ }^{13}$ We leveraged our observations to describe how the process evolved and functioned.

\section{RESULTS}

We used the split-session focus group approach in 4 practices. In each practice, 2 to 4 physicians and approximately twice as many staff participated.

Qualitative data from the focus groups revealed several general themes related to aspects missing from the PreventIT system, features needing improve-

Table 2. The Split-Session Focus Group Procedure (Morning-Start Format)

\begin{tabular}{|c|c|c|c|}
\hline Session ${ }^{a}$ & Participants & Activity & Comment \\
\hline 1 & Staff and physicians & $\begin{array}{l}\text { Role play followed by short ques- } \\
\text { tion and answer for general issues }\end{array}$ & $\begin{array}{l}\text { Joint whole-group format allows general exposure, understanding, } \\
\text { and questions }\end{array}$ \\
\hline 2 & Physicians only & $\begin{array}{l}\text { Focus group interview: physician- } \\
\text { specific issues are addressed }\end{array}$ & Provides staff time to prepare patients for physician clinical care \\
\hline 3 & Staff only & $\begin{array}{l}\text { Focus group interview: staff-specific } \\
\text { issues are addressed }\end{array}$ & $\begin{array}{l}\text { Staff often finish early, while physicians often run late; focus group } \\
\text { interview is more convenient with staff during their lunch break } \\
\text { while still leaving some time for lunch }\end{array}$ \\
\hline
\end{tabular}


ment, clarifying who would be responsible for entering and updating information, enhancing overall user-friendliness, and rethinking how to incorporate the system into the patient visit. The findings of the split-session focus groups were useful for enhancing PreventIT, and some features developed for the prototype were ultimately incorporated into a commercial product line.

The general format of the split-session focus group is presented in Table 2, which illustrates the morningstart approach. The focus group interviews were conducted in 3 sessions, each lasting 30 minutes. In the first session, the entire office staff and physicians participated in an overview of the PreventIT system, which included a role play to introduce the system. The role play consisted of a dialog between a patient and physician similar to that in a routine physical visit, but integrating the new PreventIT system into the conversation. A physician-researcher performed the physician role, and the moderator of the focus groups performed the patient role. After the role play and time for general questions, the physician-researcher left, and the staff were dismissed. This second session allowed the focus group moderator to hone in on questions relevant only to the physicians. Thereafter, the moderator completed a third session with the office staff only. This format allowed all participants to see the same role play presentation of material in the full-group session, but then to have questions tailored to work roles in the split sessions.

As a variation of the morning-start format of the split-focus group procedure, we used a lunch-start format in offices where this strategy fit better with the practice's workflow. In this format, the first session is conducted with staff immediately after morning patient care ended around noon. The rationale for this approach is that staff finish morning patient care before physicians do, so there is a window of time when the physicians are unavailable. The second session involves both the staff and physicians because at this point, the physicians generally have finished patient care. The final session involves physicians only; staff can leave for afternoon patient check-in and rooming.

Qualitative comments from physicians and staff concerning the split-session format were uniformly positive. For instance, a staff member said the format, "helped us work within our existing patient schedule." During staff-only interviews, the staff openly noted aspects of the system that would require more work for themselves, such as printing and filing; their comments suggested that they were not inhibited in responding.

This study did not have a comparison group wherein sessions were conducted in a neutral setting. We observed, however, that in the office setting, the focus groups ran smoothly, and participants appeared comfortable being on their own turf during the split focus group sessions.

\section{DISCUSSION}

We found that use of the office-based naturalistic setting and the split-session approach to focus groups was feasible, efficient, effective, and well received. With this approach, we were able to collect rich, candid qualitative data on the PreventIT system from diverse stakeholders in the environment where work took place.

As shown in Table 3, there may be advantages and disadvantages to both the natural office setting and an off-site neutral setting. Conducting the focus group interviews in the office promotes time efficiency for the practice participants, as they can perform their work around the focus groups with no need to travel elsewhere. As work distribution ebbs and flows during the day, our physician-researchers felt the split-session schedule helped minimize impact on practice productivity based on usual flow, that is, staff were busiest at the beginning of the half-day and physicians were busiest at the end. Although it is difficult to document, we believe that holding sessions in the workplace addition-
Table 3. Advantages and Disadvantages of Focus Group Interviews in Naturalistic Settings and Neutral Settings

\begin{tabular}{|c|c|c|}
\hline Setting & Advantages & Disadvantages \\
\hline \multirow[t]{5}{*}{ Naturalistic } & Convenience for participants & Potential distraction by impending \\
\hline & Participant comfort in the setting & work to be done when focus group \\
\hline & $\begin{array}{l}\text { Immersion in environmental stimuli } \\
\text { and setting, allowing for consider- } \\
\text { ation of application of the proposed }\end{array}$ & $\begin{array}{l}\text { Possible reluctance to criticize own } \\
\text { office's procedures }\end{array}$ \\
\hline & $\begin{array}{l}\text { technologic intervention in their } \\
\text { office }\end{array}$ & $\begin{array}{l}\text { Potential lack of space in practice to } \\
\text { hold sessions }\end{array}$ \\
\hline & $\begin{array}{l}\text { Simple payment mechanism: office } \\
\text { receives lump sum for participation }\end{array}$ & $\begin{array}{l}\text { Compensation to the practice may } \\
\text { have limited benefit for office staff }\end{array}$ \\
\hline \multirow[t]{4}{*}{ Neutral } & $\begin{array}{l}\text { Lack of distraction by environmental } \\
\text { stimuli }\end{array}$ & $\begin{array}{l}\text { Need to travel to the location chosen } \\
\text { for session }\end{array}$ \\
\hline & $\begin{array}{l}\text { Lack of distraction by immediacy of } \\
\text { the time clock }\end{array}$ & $\begin{array}{l}\text { Expectation that staff members will } \\
\text { use their lunch time to participate }\end{array}$ \\
\hline & $\begin{array}{l}\text { Potential sense of security in voicing } \\
\text { opinion, especially if negative, about } \\
\text { the system under investigation }\end{array}$ & \\
\hline & $\begin{array}{l}\text { Freedom to use the participation } \\
\text { incentive as desired }\end{array}$ & \\
\hline
\end{tabular}




\begin{tabular}{|c|c|c|}
\hline $\begin{array}{l}\text { Focus Group } \\
\text { Approach }\end{array}$ & Advantages & Disadvantages \\
\hline Split session & $\begin{array}{l}\text { Fits into existing practice } \\
\text { workflow } \\
\text { Generates dialog and interac- } \\
\text { tion among the full group } \\
\text { Allows gathering of data from } \\
\text { distinct subgroups having } \\
\text { different perspectives } \\
\text { Permits staff and physicians } \\
\text { to speak freely without the } \\
\text { other present } \\
\text { Allows recruitment of more } \\
\text { participants for each session } \\
\text { Nets an overall cost savings }\end{array}$ & $\begin{array}{l}\text { Requires that practice must be willing to } \\
\text { accommodate focus group interviews } \\
\text { at their location } \\
\text { Necessitates a conference room, waiting } \\
\text { room, or other suitable area be avail- } \\
\text { able on site to conduct sessions } \\
\text { Limits time with subgroups, which may } \\
\text { yield less rich data }\end{array}$ \\
\hline $\begin{array}{l}\text { Traditional } \\
\text { (unsplit) }\end{array}$ & $\begin{array}{l}\text { Allows ability to conduct mul- } \\
\text { tiple groups at one time } \\
\text { Enables bringing together } \\
\text { participants from multiple } \\
\text { practices at once }\end{array}$ & $\begin{array}{l}\text { Yields lower participation rates } \\
\text { Requires participants to travel to location } \\
\text { May constrain staff and physicians from } \\
\text { speaking freely when other is present } \\
\text { May require additional incentives }\end{array}$ \\
\hline
\end{tabular}

tion and role play triggered staff to think about how the system could fit into their workflow during the morning patient care session and allowed them to voice these ideas during the subsequent session over lunch.

With the lunch-start format, neither staff nor physicians consistently finished their morning work simultaneously. This issue created inefficiency. The demands of patient care invariably meant that someone would arrive late. In our experience, the lunch start was inefficient as we always spent down time waiting to establish a quorum. This format is more efficient from a time perspective of the moderator, however, as the morning start requires being present throughout

ally allowed participants to put the role playing and questioning into context.

The split-session focus group approach merits consideration for researchers who work in primary care or other outpatient offices and need to collect data from both physicians and other members of the health care team (Table 4). Compared with traditional focus groups, the split-session approach had 3 key advantages: efficiency, minimization of issues of social and professional hierarchy, and ability to incorporate subgroup-appropriate questions (eg, cost considerations in the physician-only group). The procedures we used allowed efficient participation of both physicians and office staff. The split-session approach was designed to integrate into the existing practice workflow, and the participating practices confirmed this efficiency. Regarding differences in social and professional stature between participants (eg, physicians vs medical assistants), the split-session approach allows for interactivity among the whole group, while also encouraging professionally and socially less empowered team members, who may feel threatened by their superiors, ${ }^{7,14}$ to speak their minds. The splitsession approach thus allows staff to voice their opinions unencumbered by physician presence. Similarly, unencumbered by the presence of staff, physicians can talk candidly about staff limitations or exemplary staff without stigmatizing poor-performing individuals or appearing to show favoritism to others.

On the basis of our experience, we favor the morning-start format over the lunch-start format as it is easier to begin on time. An additional advantage of starting in the morning was that the system introduc- the entire morning of patient care and into the lunch hour. Additionally, the lunch start enables a continuous flow and is completed more quickly.

Dividing a group into multiple smaller focus groups to conduct interviews is a common strategy; however, using a split-session focus group approach that begins with a whole-group session and continues with subgroup sessions in family physician offices is a novel and unique contribution. This strategy realizes the benefits of the traditional focus group approach while adding those enabled by strategically planned subgroups.

In summary, the split-session strategy to focus groups provides flexibility for researchers to collect data in the naturalistic office setting and simultaneously accommodate a practice's workflow needs as much as possible. By holding the interviews at the practice, we anticipate it will be easier to attain higher rates of participation of both physicians and practice staff. Relative to traditional focus groups, office-based split-session focus groups allow efficiency and a greater degree of tailoring interview questions to specific subgroups. We recommend use of the split-session focus group process as a means of collecting comprehensive, reliable, and rich qualitative data from diverse members of health care teams.

To read or post commentaries in response to this article, see it online at http://www.annfammed.org/content/14/1/70.

Key words: focus groups; qualitative research; research methodology; research design; clinical study; family practice; primary health care

Submitted March 17, 2011; submitted, revised, September 8, 2015; accepted September 15, 2015. 
Funding support: The Centers for Disease Control and Prevention supported this project, Improving Prevention Delivery Using an Interactive Technology System (PreventIT), grant number R43 DP000316-01.

\section{References}

1. Office of Behavioral and Social Sciences Research, National Institutes of Health. Qualitative Methods in Health Research: Opportunities and Considerations in Application and Review. Bethesda, MD: National Institutes of Health; 2001. NIH publication 02-5046.

2. Greenbaum T. Focus groups with physicians have different requirements than those with consumers. Quirk's Marketing Research Review. 1992;6(1):14-15,30.

3. Kitzinger J. Qualitative research. Introducing focus groups. BMJ. 1995;311(7000):299-302.

4. Krueger RA. Focus Groups: A Practical Guide for Applied Research. 2nd ed. Thousand Oaks, CA: SAGE Publications, Inc; 1994.

5. Morgan DL. Focus Groups as Qualitative Research. Vol 16. Newbury Park, CA: SAGE Publications, Inc; 1988.

6. Merton R, Riske M, Kendall PL. The Focused Interview. New York, NY: Free Press; 1956.
7. Madriz E. Focus groups in feminist research. In: Denzin NK, Lincoln YS, eds. Handbook of Qualitative Research. Thousand Oaks, CA: SAGE Publications, Inc; 2000:835-850.

8. Fontana A, Frey JH. The interview: from structured questions to negotiated text. In: Denzin NK, Lincoln YS, eds. Handbook of Qualitative Research. Thousand Oaks, CA: SAGE Publications, Inc; 2000:645-672.

9. Webb C, Kevern J. Focus groups as a research method: a critique of some aspects of their use in nursing research. J Adv Nurs. 2001;33(6):798-805.

10. Millward LJ. Focus groups. In: Breakwell GM, Smith JA, Wright DB, eds. Research Methods in Psychology. London, England: SAGE Publications Inc; 2012:411-437.

11. Stewart DW, Shamdasani PN. Focus Groups: Theory and Practice. 3rd ed. Thousand Oaks, CA: SAGE Publications, Inc; 2015.

12. Krueger RA, Casey MA. Focus Groups: A Practical Guide for Applied Research. 4th ed. Thousand Oaks, CA: SAGE Publications, Inc; 2009.

13. Crabtree BF, Miller WL. Doing Qualitative Research. 2nd ed. Thousand Oaks, CA: SAGE Publications, Inc; 1999.

14. Mikecz R. Interviewing elites: addressing methodological issues. Qual Inq. 2012;18(6):482-493.

\section{Get the Annals of Family Medicine by E-mail}

Make sure you see every new issue

while it's fresh; have the table of

contents sent to you by e-mail for

easy access to articles of interest.

Don't miss important research.

Request the e-mail table of contents at

http://www2.highroadsolution.com/

aafp_annals_preference_center/search.aspx
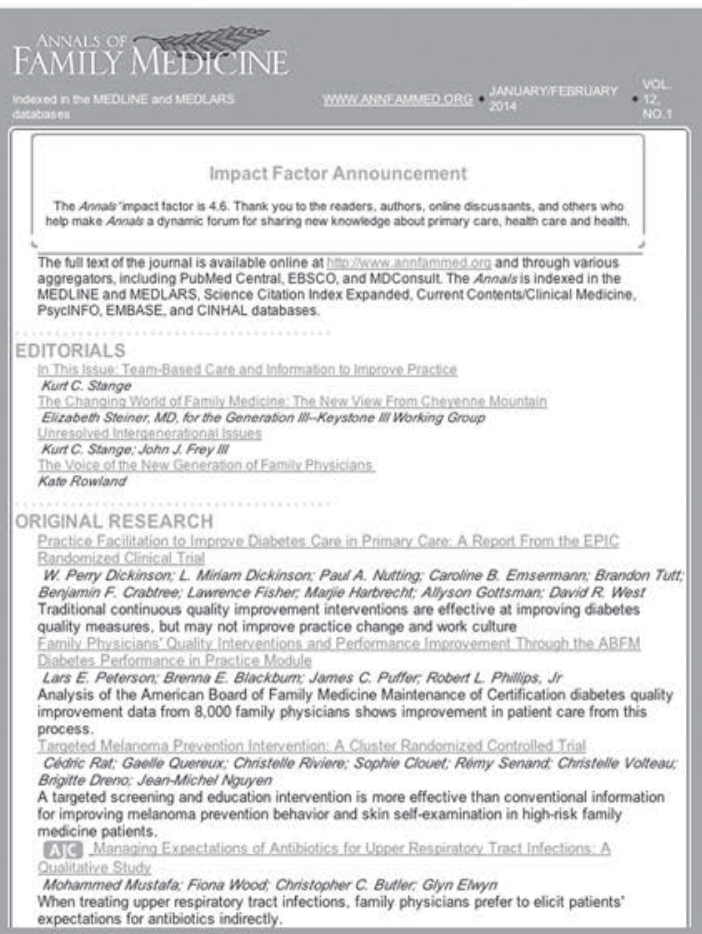